(2) Open Access Full Text Article

\title{
Assessing the relationship between the level of pain control and patient satisfaction
}

This article was published in the following Dove Press journal:

Journal of Pain Research

7 September 2013

Number of times this article has been viewed

\author{
Shay Phillips' \\ Maja Gift ${ }^{2}$ \\ Shyam Gelot ${ }^{3}$ \\ Minh Duong ${ }^{2}$ \\ Hazel Tapp' \\ 'Carolinas Medical Center, \\ Department of Family Medicine, \\ University of North Carolina at \\ Chapel Hill, School of Medicine, \\ Chapel Hill, NC, USA; ${ }^{2}$ Department \\ of Pharmacy Services, Tampa General \\ Hospital, Tampa, FL, USA; '3niversity \\ of South Florida College of Pharmacy, \\ Tampa, FL, USA
}

Purpose: The primary assessment tool used by hospitals to measure the outcomes of pain management programs is the $0-10$ numerical pain rating scale. However, it is unclear if this assessment should be used as the sole indicator of positive outcomes by pain management programs. Although it is assumed that pain intensity scores would be correlated with patient satisfaction, few studies have evaluated the association between pain intensity scores and patient satisfaction.

Methods: In this pilot study, we investigated the relationship between pain intensity and patient satisfaction by evaluating 88 patients who received opioid analgesics at a 1018-bed acute care institution. A 14-question survey was adapted from a questionnaire developed by the American Pain Society to assess patient pain control and overall satisfaction with our institution's pain management strategies.

Results: This study found no association between pain intensity score and patient satisfaction with overall pain management (Spearman's rank correlation coefficient $=-0.31 ; 95 \%$ confidence interval $=-0.79$ to 0.39 ). The majority of the surveyed patients were satisfied or very satisfied with their overall pain management, regardless of their pain intensity score.

Conclusion: These findings contribute to the general understanding that institutions should use pain intensity scores together with a measure of patient pain satisfaction when assessing regulatory and quality control programs.

Keywords: pain management, pain assessment, pain intensity scores, perception, measurement, HCAHPS survey

\section{Introduction}

Since 2001 when the Joint Commission designated pain as the fifth vital sign, health care professionals have become increasingly aware of appropriate pain management strategies and the need to assess pain management outcomes. ${ }^{1}$ The American Pain Society Quality of Care Committee first developed quality improvement guidelines and programs to improve the treatment outcomes of patients with acute pain and cancer pain. ${ }^{2}$ These guidelines focused on increasing awareness of pain in clinical environments and led to pain being classified as the fifth vital sign. The committee recognized the magnitude of the problem and set forth standards to improve pain management. The ability to assess pain outcomes is critical to improving pain management. Traditionally, the assessment of pain outcomes has been conducted by measuring each patient's subjective level of pain control using pain intensity scales, most commonly the $0-10$ numerical scale (with 0 being no pain and 10 being the worst pain imaginable). The singular use of this tool, however, carries clinical limitations. This scale does not take into account multifaceted approaches to pain management, which

\footnotetext{
Correspondence: Shyam Gelot, PharmD, BCPS University of South Florida College of Pharmacy, Department of Pharmacotherapeutics and Clinical Research, I290I Bruce B Downs Blvd, MDC 30, Tampa, FI 336I2, USA

Tel +I 813974 II 24

Email sgelot@health.usf.edu
} 
should not only include the concept of adequate pain control but also patient satisfaction with pain control. ${ }^{3}$

Another major limitation of the use of pain-rating scales as the primary assessment tool is the false perception that a low pain intensity score is clinically suggestive of positive patient outcomes and/or satisfaction (and vice versa). Few studies have solely investigated the association between pain intensity and patient satisfaction with pain control.

A recent review of the literature reported conflicting evidence regarding the association between patient satisfaction and pain. In a 2012 study, patient perception of pain control was assessed in surgical units. The authors concluded that the odds of patient satisfaction were 4.86 times greater if pain was controlled and 9.92 times greater if the patient considered the health care staff's attempts to relieve pain to be sufficient. ${ }^{4}$ Pellino and Ward ${ }^{5}$ explored the puzzling relationship between pain and satisfaction using the concept of "perceived control." Their study reported that an inverse relationship exists with the patient's perception of pain control and their level of satisfaction. Donovan ${ }^{6}$ reported that while $75 \%$ of postoperative patients reported significant pain, $86 \%$ of patients reported that they were satisfied with their pain relief. Chung and Lui ${ }^{7}$ reported a similar trend: $85 \%$ of postoperative patients reported varying degrees of pain, while $>65 \%$ of patients were satisfied with the pain management they received. Additionally, Weis et $\mathrm{al}^{8}$ reported that even though $43 \%$ of patients rated their pain as moderate to severe, $75 \%$ of patients were satisfied with the level of postoperative pain relief that they received.

More recent studies evaluating patient pain (including patients with cancer and burns) report similar trends despite high levels of pain, and most patients reported they were satisfied with the pain management they received. ${ }^{9-12}$ In contrast, Miaskowski et $\mathrm{l}^{13}$ reported that "patients with the highest pain intensity score were the most dissatisfied with their level of pain relief," indicating a positive association between pain control and satisfaction. A 2001 study conducted at a large metropolitan emergency room evaluated the correlation between patient satisfaction, pain management (rated as "very good," "good," "so-so," or "poor"), and pain scores determined using the visual analog scale (VAS) in 54 patients. ${ }^{14}$ The study concluded that patient satisfaction is not correlated with the initial VAS pain score $(r=0.202)$, VAS score at discharge $(r=0.146)$, verbally stated assessment of pain at discharge $(r=0.122)$, or changes in VAS pain scores between presentation and discharge $(\mathrm{r}=-0.075)$. As reported by a few studies, $4,5,7,10,11,14$ the association between pain control and satisfaction is a complex relationship and further studies are warranted. However, the degree of patient satisfaction could simply be a reflection of the performance of the health care providers and not an indication of the efficaciousness of pain management.

One would expect that patients with low pain intensity scores would be satisfied with their pain management outcomes and patients with high pain intensity scores would be dissatisfied; however, this relationship is not always consistent. Patients who report high pain intensity scores may report that they are satisfied with their overall pain management outcomes and vice versa. This paradoxical effect is clinically relevant but has not been fully examined. This pilot study addresses the question, "How are pain scores related to patient satisfaction?"

The purpose of this study is to evaluate the relationship between pain control and patient satisfaction. Two relationships between pain control and satisfaction are possible: (1) positive association between a high level of patient satisfaction with good pain control and (2) a negative association between a high level of satisfaction with poor pain control.

\section{Methods}

The surveyed population included patients on the general surgery, posttrauma, and oncology wards who were prescribed opioid analgesics. A daily Pyxis ${ }^{\circledR}$ report (Pyxis Corporation a Cardinal Health Company, Diego, CA, USA) was used to identify the surveyed patient population. The sample size required to accurately reflect these effects was calculated to be 138 patients ( $95 \%$ power; $\alpha=0.05$ ). We estimated that 150 patients would participate in the study over a 7-day period based on the hospital records stating the number of patients receiving opioid analgesics on the general surgery, posttrauma, and oncology wards.

The patients identified in the hospital records were screened and classified according to the inclusion and exclusion criteria. Inclusion criteria included literate English-speaking patients $>18$ years of age who were able to self-report their condition and were receiving opioid analgesics on an "as needed" and/or scheduled regimen. Patients with a history of substance abuse (as documented in their medical records), nonverbal patients (eg, intubated patients), and patients who were admitted for $<1$ day were excluded from this study. All patients who met the inclusion criteria $(\mathrm{n}=150)$ were asked to voluntarily participate in this study. No randomization protocols were used.

Patients were provided an introductory letter describing the project, the study survey, and a return envelope 
with specific directions to seal the completed survey in the provided envelope. Surveys were collected daily by the primary investigator (SP). The 14-question survey, as shown in Table 1, was adapted from the American Pain Society's Patient Outcome Questionnaire and the Patient Opinion of Pain Management Tool. ${ }^{2,15}$ This survey was used to examine different aspects of pain intensity and satisfaction. Pain intensity was measured by asking each patient to evaluate their current, most severe, and average pain levels within the last 24 hours (questions 5-7), and patient satisfaction was also measured (questions 8-14). The majority of the respondents were female (63\%) and Caucasian (67\%; Table 2). The average age of the patient population was $51 \pm 17$ years.

Of 88 surveys collected, 78 patients reported their level of pain within the past 24 hours and 76 patients reported their overall level of satisfaction. Therefore, a total of 76 surveys were used to analyze the relationship between pain and satisfaction. When evaluating the relationship between pain intensity and satisfaction, this study used survey questions 7 and 14 to identify possible correlations.

A completed survey implied voluntary informed consent; therefore, a separate informed consent document was not required. Patients were provided a complimentary pen as an incentive to complete the survey. All surveys, whether complete or partially complete, were analyzed and reported. Spearman's rank correlation coefficients were calculated to determine the relationship between the patient's level of pain and satisfaction with pain control. Our hospital's institutional review board approved the study.

\section{Results}

In total, 288 surveys were distributed to patients on the general surgery, posttrauma, and oncology wards in order to assess pain control and patient satisfaction (Table 1). Of these, 88 surveys were returned ( $31 \%$ response rate). Most patients (89\%) reported experiencing pain in the previous 24 hours. Seventy-eight patients responded to survey questions 5-7, which are qualitative questions designed to assess each patient's current, average, and worst levels of pain control over the previous 24 hours (Table 3 ). Thirty-three patients $(42 \%)$ reported a pain score $>5$ at the time they completed the survey (question 5). The worst pain score reported over the previous 24-hour period (question 6) demonstrated a mean \pm standard deviation of $7.6 \pm 2.3$. When patients were asked to report their average level of pain over the past 24-hour period (survey question 7), 51\% (39 of 76 patients) reported a pain score $>5$, demonstrating a mean pain score of $5.5 \pm 2.3$ for all respondents (Figure 1).
Survey questions 8-14 are quantitative questions designed to assess patient satisfaction with pain control and evaluate the various factors that contribute to patient satisfaction (Table 3 ). In total, $49 \%$ and $51 \%$ of respondents reported that they were "very satisfied" with how their nurses and physicians, respectively, responded to their complaints regarding pain. The survey question regarding waiting times for the administration of pain medication demonstrated varying results (question 10; Table 1). Among respondents who requested pain medication, $42 \%$ received medication within 10 minutes of asking, $17 \%$ within 11-20 minutes, $12 \%$ within $21-30$ minutes, $15 \%$ within $31-60$ minutes, and $14 \%$ of patients waited $>1$ hour or never received medication at all. Three patients did not respond to this survey question, one patient reported having asked for but never receiving medication, and three patients never asked for pain medication. Correlations between several factors, such as wait time and patient satisfaction, were expected but are not reported here. The paradoxical reasons for high satisfaction scores despite varying wait times are most likely multifactorial and due to the each patient's overall experience, which was previously reported to be highly correlated with patient satisfaction and the level of care provided by the hospital staff. ${ }^{12}$ Eighty-seven percent of patients reported that their health care providers provided information regarding pain control. When asked about their overall level of satisfaction, 76 patients provided a response. Overall, the majority of patients reported being "satisfied" (34 of 76 patients; 44.7\%) or "very satisfied" (31 of 76 patients; $40.8 \%$ ) with the results of their pain treatment strategies (Figure 2). Figure 3 shows the relationship between pain control and satisfaction. Spearman's rank correlation coefficients were calculated to determine the relationship between each patient's level of pain and their satisfaction with pain control. Based on the 76 participants who answered both survey questions, the correlation coefficient was determined to be $r=-0.31(95 \%$ confidence interval $=-0.79$ to 0.39$)$. A slight, but nonsignificant, downward trend line was observed (ie, satisfaction decreased as the level of pain increased and vice versa). This negative correlation was not significantly different from 0 , as implied by the $95 \%$ confidence interval, indicating the insignificance of the trend line.

\section{Discussion}

To date, few studies have investigated the direct association between pain intensity scores and patient satisfaction, either overall or in terms of clinical outcomes. Stahmer et $\mathrm{al}^{16}$ reported that patient satisfaction with pain management is associated with the amount of pain relief achieved. Considering the overall high level of satisfaction, it appears 
Table I Pain and satisfaction survey administered to all study participants

I. Age:

2. Sex (check one): $\square$ Male

$\square$ Female

3. Race (check all that apply):
$\square$ Asian
$\square$ Middle Eastern
$\square$ White/Caucasian
$\square$ Black/African descent
$\square$ Native American
$\square$ Other
$\square$ East Indian
$\square$ Pacific Islander
$\square$ Hispanic/Latino

4. Have you experienced any pain in the past 24 hours (check one)? Yes No

If you answered "No" to this question, please stop now and return your survey to your nurse. If you answered "Yes," complete the survey.

5. On this scale, how much pain are you having right now?
0
2
3
45
6
7
8
9
10
No pain

6. On this scale, indicate the worst pain you have had in the past 24 hours.

$\begin{array}{llllllllll}0 & 1 & 2 & 3 & 4 & 5 & 6 & 7 & 8 & 9 \\ \text { No pain } & & & & & & & & \text { Worst pain possible }\end{array}$

7. On this scale, indicate the average level pain you have had in the past 24 hours.

$\begin{array}{llllllllll}0 & 1 & 2 & 3 & 4 & 5 & 6 & 7 & 8 & 9 \\ \text { No pain }\end{array}$

8. Select the phrase that indicates how satisfied or dissatisfied you are with how the nurses responded to your reports of pain.

$\begin{array}{ll}\text { Very dissatisfied } & \text { Slightly satisfied } \\ \text { Dissatisfied } & \text { Satisfied } \\ \text { Slightly dissatisfied } & \text { Very satisfied }\end{array}$

9. Select the phrase that indicated how satisfied or dissatisfied you are with how the doctors responded to your reports of pain.

$\begin{array}{ll}\text { Very dissatisfied } & \text { Slightly satisfied } \\ \text { Dissatisfied } & \text { Satisfied } \\ \text { Slightly dissatisfied } & \quad \text { Very satisfied }\end{array}$

10. When you asked for pain medication, what was the longest time you had to wait to get it?

$\begin{array}{ll}\text { Less than } 10 \text { minutes } & \text { More than I hour } \\ \text { II-20 minutes } & \text { Asked, but never received medication } \\ \text { 2I-30 minutes } & - \text { Never asked for pain medication } \\ 3 \text { II-60 minutes } & -\end{array}$

II. Was there a time that the medication you were given for pain didn't help and you asked

for something more or different to relieve the pain? Yes No

If you answered "Yes," how long did it take before your doctor or nurse changed your treatment to a stronger or different medication and gave it to you?
I hour
3-4 hours
9-24 hours
I-2 hours
$5-8$ hours
More than I day

Earlier in your care, did a physician or nurse make it clear to you that we consider treatment of pain very important and that you should be sure to tell them when you have pain?

Yes No 


\section{Table I}

12. Were you given the opportunity for peace and quiet so that you could sleep at night?

$\begin{array}{ll}\text { Yes } & \text { No } \\ \text { Select the phrase that indicates how satisfied or dissatisfied } & \\ \text { Very dissatisfied } & \text { Slightly satisfied } \\ \text { Dissatisfied } & \text { Satisfied } \\ \text { Slightly dissatisfied } & \text { Very satisfied }\end{array}$

Notes: Adapted with permission Copyright $\odot$ 1995, American Medical Asociation. All rights reserved. Quality improvement guidelines for the treatment of acute pain and cancer pain. American Pain Society Quality of Care Committee. JAMA. 1995;274(23):1874-1880. ${ }^{2}$

Reprinted from J Pain Symptom Manage, Vol I8(I), Calvin A, Becker H, Biering P, Grobe S, Measuring patient opinion of pain management, 17-26, Copyright 1999, with permission from Elsevier. ${ }^{15}$

that pain relief alone is not the only factor that affects patient satisfaction with pain management (Figure 4). ${ }^{16}$

Muller-Staub et al ${ }^{17}$ reported statistically significant correlations between worry, pain, anxiety, and patient satisfaction. In one study, a negative correlation was found between satisfaction and pain intensity,$^{18}$ and in another study $81 \%$ of patients claimed to be satisfied with their pain management despite high pain scores. Age is also correlated with higher satisfaction. ${ }^{19}$

A misconception held by many health care practitioners is that low pain intensity scores are indicative of positive patient satisfaction and that high pain intensity scores are indicative of negative patient satisfaction. Indeed, there is a tremendous biopsychosocial element to pain that should not be ignored and could explain why the use of pain severity scales as the sole measure of clinical outcomes is suboptimal. Physicians and nurses are aware of the daunting task of educating patients about the importance of pain control. The number of interruptions made by the nursing staff during the night can also influence the patient's level of satisfaction (ie, patients who report a high number of interruptions may report low levels of satisfaction).

Table 2 Participant demographics

\begin{tabular}{lll}
\hline $\begin{array}{l}\text { Characteristics of the study } \\
\text { participants }\end{array}$ & $\mathbf{n}$ & $\%$ \\
\hline Age (years \pm SD) & $51 \pm 17$ & \\
Sex & 31 & 35.2 \\
Male & 55 & 62.5 \\
Female & 2 & 2.3 \\
$\quad$ Unspecified & 59 & 67 \\
Race & 15 & 17 \\
Caucasian & 8 & 9 \\
African American & 6 & 7 \\
Hispanic/Latino & & \\
Other & &
\end{tabular}

Abbreviations: $n$, number; SD, standard deviation.
While this study demonstrates the importance of addressing patient satisfaction as an independent variable of pain management, the strength of this study could be limited by the fact that we used a self-reported survey; therefore, the results are not validated. Like most surveys, this study is subject to both response and nonresponse bias. In terms of response bias, patients may answer survey questions by reporting how they think the questions should be answered

Table 3 Relevant survey responses regarding pain control and patient satisfaction

\begin{tabular}{|c|c|c|}
\hline Survey question & $\begin{array}{l}\text { Response } \\
\text { rate }\end{array}$ & $\begin{array}{l}\text { Survey scorel } \\
\text { response }\end{array}$ \\
\hline Question 5 & $33 / 78(42 \%)$ & Mean \pm SD \\
\hline Patients reporting pain score $>5$ & & pain score: $7 \pm 4$ \\
\hline Question 6 & $64 / 78(82 \%)$ & Mean \pm SD \\
\hline Patients reporting pain score $>5$ & & pain score: $7.6 \pm 2.3$ \\
\hline Question 7 & $39 / 76(51 \%)$ & Mean \pm SD \\
\hline Patients reporting pain score $>5$ & & pain score: $5.6 \pm 2.3$ \\
\hline \multirow[t]{2}{*}{ Question 8} & $27 / 78(35 \%)$ & Satisfied \\
\hline & $38 / 78(49 \%)$ & Very satisfied \\
\hline \multirow[t]{2}{*}{ Question 9} & $30 / 78(50 \%)$ & Satisfied \\
\hline & $39 / 78(50 \%)$ & Very satisfied \\
\hline \multirow[t]{6}{*}{ Question 10} & $30 / 72(42 \%)$ & $<10$ minutes \\
\hline & $12 / 72(17 \%)$ & II-20 minutes \\
\hline & $9 / 72(12 \%)$ & $21-30$ minutes \\
\hline & $1 \mathrm{I} / 72(15 \%)$ & $31-60$ minutes \\
\hline & $1 \mathrm{I} / 72(14 \%)$ & $>I$ hour or never \\
\hline & & received medication \\
\hline \multirow[t]{6}{*}{ Question II } & $13 / 29(45 \%)$ & $<\mathrm{I}$ hour \\
\hline & $4 / 29(14 \%)$ & I-2 hours \\
\hline & $4 / 29$ (14\%) & $3-4$ hours \\
\hline & $2 / 29(7 \%)$ & $5-8$ hours \\
\hline & $4 / 29(14 \%)$ & 9-24 hours \\
\hline & $0 / 29$ & $>24$ hours \\
\hline Question 12 & $97 / 78(86 \%)$ & Yes \\
\hline \multirow[t]{2}{*}{ Question 13} & $66 / 78(87 \%)$ & Yes \\
\hline & $10 / 78(13 \%)$ & No \\
\hline \multirow[t]{2}{*}{ Question 14} & $34 / 76(45 \%)$ & Satisfied \\
\hline & $3 \mid / 76(4 \mid \%)$ & Very satisfied \\
\hline
\end{tabular}

Abbreviation: SD, standard deviation. 


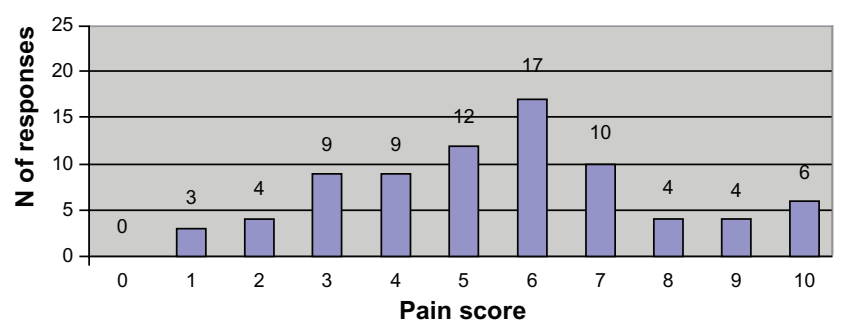

Figure I Distribution of the pain scores reported for the previous 24-hour period $(n=78)$.

Note: Average pain score $=5.6 \pm 2.3$.

Abbreviation: $n$, number.

instead of how they truly feel. In addition, some patients may respond to survey questions by reporting the most extreme response, especially if they experienced a positive or negative encounter with a health care provider that day. Another factor that cannot be ruled out is the biases of family members who help the patient complete the survey.

Regarding nonresponse bias, only 76 of 88 respondents answered both segments of the survey, which addressed levels of pain and satisfaction, respectively. Incomplete surveys limit the number of surveys that can be analyzed. It was estimated that 150 completed surveys would be needed for this study. However, because only 76 completed surveys were returned, this study does not demonstrate adequate power to indicate a true correlation between patient pain scores and satisfaction (Pearson's $r$ correlation $=-0.094$; $P=0.42$ ). Another limitation is that this study did not differentiate between sources of pain. Oncology and posttrauma patients present with different pain management challenges. Future studies need to be performed on populations with the same causes of pain. In addition, the effects of race, ethnicity, age, and sex were not assessed.

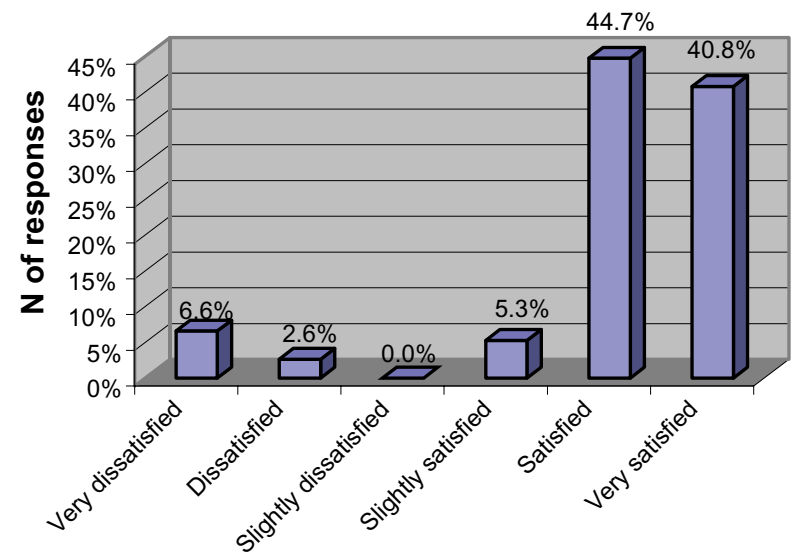

Overall level of satisfaction

Figure 2 Overall patient satisfaction with pain treatment $(n=76)$. Abbreviation: $\mathrm{n}$, number.

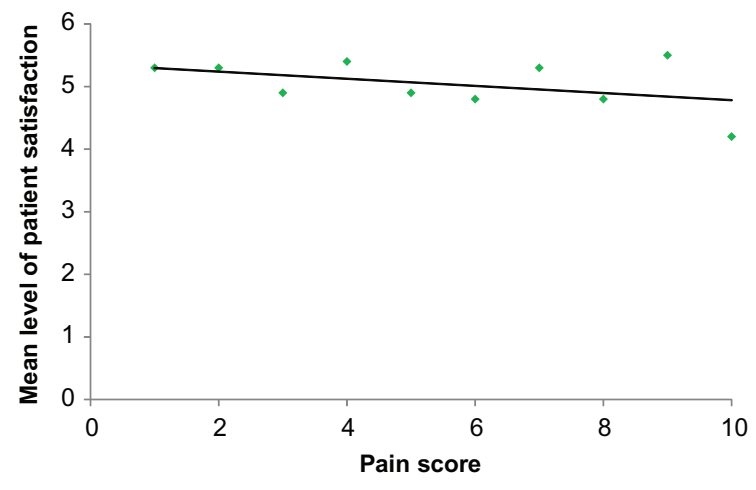

Figure 3 Relationship between patient satisfaction and pain control $(n=76)$. Note: Spearman correlation ( $95 \% \mathrm{Cl}):-0.31$ ( -0.79 to 0.39$)$.

Abbreviations: $\mathrm{n}$, number; $\mathrm{Cl}$, confidence interval.

Another limitation of this study is the response rate. The satisfactory response rate for written surveys varies enormously, but is generally about $60 \%{ }^{20}$ The power of this study is sufficient for determining a medium association between each patient's pain score and level of satisfaction, and we initially determined that 134 completed surveys would be required. Therefore, the power of this analysis is insufficient to conclusively report no association.

Data from this study and others support the notion that pain intensity is not a reliable solo predictor or indicator of a patient's satisfaction with his or her overall pain management. In an attempt to provide comparable data on patient satisfaction among hospitals, CMS collaborated with the Agency for Healthcare Research and Quality to develop the Hospital Consumer Assessment of Healthcare Providers and Systems (HCAHPS) survey. ${ }^{21}$ This survey includes 18 questions on each patient's hospital experience, ranging from cleanliness of the room to pain management. The two questions addressing pain satisfaction are: (1) "During this hospital stay, how

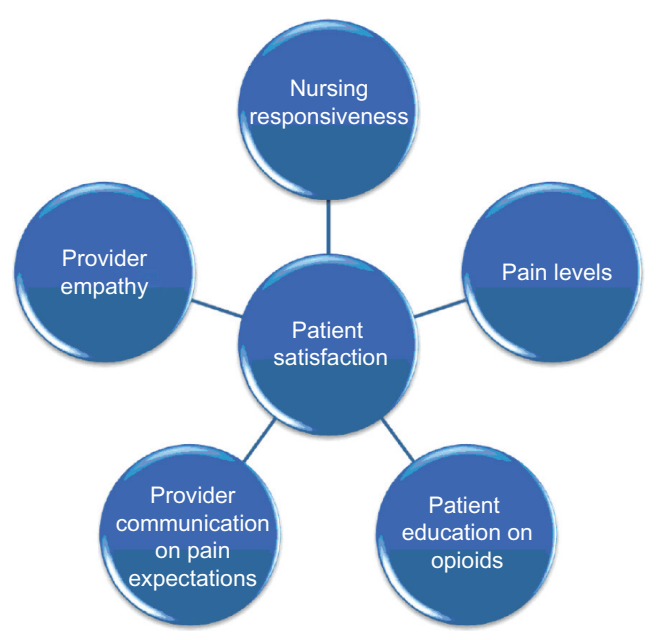

Figure 4 Factors contributing to patient satisfaction. 
often was your pain well controlled?" and (2) "During this hospital stay, how often did the hospital staff do everything they could to help you with your pain?"

The implications the HCAHPS survey has on hospitals and pain management are twofold. First, the results of the survey are publicly reported, which creates incentives for institutions to improve the public's perception of the quality of care their patients receive and, thereby, improve the institution's pain management strategies. In addition, eligible hospitals that do not participate in HCAHP surveys or submit surveys to CMS will not receive their full annual payment. $^{21}$

\section{Conclusion}

This study demonstrates no correlation between level of pain control and patient satisfaction. The majority of patients surveyed were satisfied or very satisfied with their overall pain management, regardless of their pain intensity scores. Further studies on the measurement and evaluation of pain control and patient satisfaction are warranted. Our findings supplement the available knowledge on pain management, suggesting that institutions should use pain intensity scores together with a measure of each patient's level of satisfaction with pain control as outcome measures in regulatory and quality control programs.

\section{Disclosure}

The authors report no conflicts of interest in this work.

\section{References}

1. Berry P, Dahl J. The new JCAHO pain standards: implications for pain management nurses. Pain Manag Nurs. 2000;1(1):3-12.

2. Quality improvement guidelines for the treatment of acute pain and cancer pain. American Pain Society Quality of Care Committee. JAMA. 1995;274(23):1874-1880.

3. Gordon DB, Polomano RC, Pellino T, et al. Revised American Pain Society Patient Outcome Questionnaire (APS-POQ-R) for quality improvement of pain management in hospitalized adults: preliminary psychometric evaluation. J Pain. 2010;11(11):1172-1186.

4. Hanna MN, González-Fernández M, Barrett AD, Williams KA, Pronovost P. Does patient perception of pain control affect patient satisfaction across surgical units in a tertiary teaching hospital? Am J Med Qual. 2012;27(5):411-416.

Journal of Pain Research

\section{Publish your work in this journal}

The Journal of Pain Research is an international, peer-reviewed, open access, online journal that welcomes laboratory and clinical findings in the fields of pain research and the prevention and management of pain. Original research, reviews, symposium reports, hypothesis formation and commentaries are all considered for publication.
5. Pellino TA, Ward SE. Perceived control mediates the relationship between pain severity and patient satisfaction. J Pain Symptom Manage. 1998;15(2):110-116.

6. Donovan BD. Patient attitudes to postoperative pain relief. Anaesth Intensive Care. 1983;11(2):125-129.

7. Chung JW, Lui JC. Postoperative pain management: study of patients' level of pain and satisfaction with health care providers' responsiveness to their reports of pain. Nurs Health Sci. 2003;5(1):13-21.

8. Weis OF, Sriwatanakul K, Alloza J, Weintraub M, Lasagna L. Attitudes of patients, housestaff, and nurses toward postoperative analgesic care. Anesth Analg. 1983;62(1):70-74.

9. Brown C, Constance K, Bédard D, Purden M. Colorectal surgery patients' pain status, activities, satisfaction, and beliefs about pain and pain management. Pain Manage Nurs. 2011. In press.

10. Browne AL, Andrews R, Schug SA, Wood F. Persistent pain outcomes and patient satisfaction with pain management after burn injury. Clin J Pain. 2011;27(2):136-145.

11. Panteli V, Patistea E. Assessing patients' satisfaction and intensity of pain as outcomes in the management of cancer-related pain. Eur $J$ Oncol Nurs. 2007;11(5):424-433.

12. Malouf J, Andión O, Torrubia R, Cañellas M, Baños JE. A survey of perceptions with pain management in Spanish inpatients. J Pain Symptom Manage. 2006;32(4):361-371.

13. Miaskowski C, Nichols R, Brody R, Synold T. Assessment of patient satisfaction utilizing the American Pain Society's Quality Assurance Standards on acute and cancer-related pain. J Pain Symptom Manage. 1994;9(1):5-11.

14. Kelly AM. Patient satisfaction with pain management does not correlate with initial or discharge VAS pain score, verbal pain rating at discharge, or change in VAS score in the emergency department. J Emerg Med. 2000;19(2):113-116.

15. Calvin A, Becker H, Biering P, Grobe S. Measuring patient opinion of pain management. J Pain Symptom Manage. 1999;18(1):17-26.

16. Stahmer SA, Shofer FS, Marino A, Shepard S, Abbuhl S. Do quantitative changes in pain intensity correlate with pain relief and satisfaction? Acad Emerg Med. 1998;5(9):851-857.

17. Müller-Staub M, Meer R, Briner G, Probst MT, Needham I. Measuring patient satisfaction in an emergency unit of a Swiss university hospital: occurrence of anxiety, insecurity, worry, pain, dyspnoea, nausea, thirst and hunger, and their correlation with patient satisfaction (part 2). Pflege. 2008;21(3):180-188. German.

18. McNeill JA, Sherwood GD, Starck PL, Nieto B. Pain management outcomes for hospitalized Hispanic patients. Pain Manag Nurs. 2001; 2(1):25-36.

19. Svensson I, Sjöström B, Haljamäe H. Influence of expectations and actual pain experiences on satisfaction with postoperative pain management. Eur J Pain. 2001;5(2):125-133.

20. Asch DA, Jedrziewski MK, Christakis NA. Response rates to mail surveys published in medical journals. J Clin Epidemiol. 1997;50(10): 1129-1136.

21. Centers for Medicare and Medicaid Services. Hospital Consumer Assessment of Healthcare Providers and Systems. HCHAPS Fact Sheet. Rockville, MD: Agency for Healthcare Research and Quality; 2012. Available from: http://www.hcahpsonline.org/files/HCAHPS $\% 20$ Fact\%20Sheet\%20May\%202012.pdf. Accessed March 6, 2012.

\section{Dovepress}

The manuscript management system is completely online and includes a very quick and fair peer-review system, which is all easy to use. Visit http://www.dovepress.com/testimonials.php to read real quotes from published authors. 